\title{
Student Usage And Perceptions Of The Value Of Recorded Lectures In A Traditional Face-To-Face (F2F) Class
}

Thomas L. Davies, University of South Dakota, USA

Vonda K. Cotton, University of South Dakota, USA

Leon Korte, University of South Dakota, USA

\begin{abstract}
More than ever before, today's colleges and universities are employing innovative and mutually-beneficial ways to meet the needs of students. Due to increasing competition and changing demographics, institutions benefit from attracting more students as higher enrollments generate greater revenue; these additional tuition and fees are crucial as costs continue to rise and state funding declines. Alternative course delivery modalities provide flexibility that can enable more students to obtain access to a postsecondary education as well as appeal to those with different learning styles or who are looking for a less traditional college experience. In recent years, online programs have grown significantly when compared to the traditional face-to-face $(F 2 F)$ environment. While both deliveries have their own advantages and thus supporters, each has its own disadvantages as well. As a result, blended or hybrid classes, which include features of both F2F and distance courses, are becoming more common. This article describes a study in which two sections of an F2F tax course offered students access to recorded lectures, and reports the results of a survey designed to ascertain student usage and perceptions of the value of this supplemental material.
\end{abstract}

Keywords: Face-to-Face; Blended Classes; Hybrid Classes; Recorded Lectures

\section{INTRODUCTION}

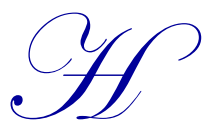
istorically, colleges and universities have operated in a face-to-face (F2F) environment where students and faculty come together in a classroom at a regularly scheduled time, often on multiple days each week. These classes primarily involve lectures where students passively receive information presented by the instructor. While these types of classes are still common at many higher education institutions, recent attention has encouraged more active student participation in the learning process. Yet F2F classes still have a number of shortcomings, including a lack of flexibility and the inability to accommodate multiple learning styles as well as different skill levels of students (El Mansour \& Mupinga, 2007). Not all students learn in the same way, and thus traditional F2F classes may not be best in meeting everyone's needs (Young, 2002). Students might also struggle with the pace of a lecture-based course where it is necessary to understand difficult content as well as take detailed notes, especially in large classes (Yoon \& Sneddon, 2011). In these large lecture courses, students retain less information, are not as motivated to learn, and may not develop as extensive higherorder thinking skills as those in smaller, more interactive classes (McKeachie, Pintrich, Lin, Smith, \& Sharma, 1986). Students may get more out of classroom activities if they know course material is also available to them outside of class, as they can then focus more on understanding the content rather than taking notes.

Today the use of technology in higher education has become more commonplace as academia attempts to meet the needs of Generation $\mathrm{X}$ and millennial students who have grown up in the information technology age (Clark \& Mayer, 2007). These students frequently have more computer expertise than their professors (Tapscott, 1997), and expect technology to be used in an academic setting. Yet, acceptance of technology-oriented instruction such as online offerings by faculty has remained stagnant at best and may be declining (Palmer, O'Donnell, Ren, \& Henker (2014). An instructor's ultimate decision to adopt technology in classes, as well as the timing of its adoption, 
depends upon several interrelated factors, including the faculty member's attitude, professional characteristics and perception of its value (Dey, Burn, \& Gerdes, 2009). Adoption decisions can also be influenced by institutional factors such as rewards, classroom infrastructures and institutional information technology resources (Dey et al., 2009). Advances in technology have provided the opportunity to address some of the aforementioned deficiencies found in more traditional settings. Regardless of how a class is delivered, technology can aid in the exploration and integration of information, and facilitate high-level thinking and engagement (American Council on Education, 2005).

According to Doering, Hughes, and Huffman (2003), increasing expectations for technical integration in academia have resulted in the growth of utilizing online technologies in traditional F2F classes as well as distance education. The latter includes online classes as well as mixed and adjunct courses. In mixed courses, considerable online learning activities such as meetings are used in place of face-to-face instruction, while in adjunct classes, online meetings and activities are a less significant component designed to supplement a traditional course (Ho \& Burniske, 2005). The distinction between mixed and adjunct offerings is often minimalized by use of the terms blended or hybrid courses, which combine elements of F2F instruction and distance teaching (Lorenzetti, 2004).

Online classes, which are taught through the use of Internet technology, are a growing segment of postsecondary education (Palmer et al., 2014). Online learning is typically asynchronous, meaning that the parties do not generally interact simultaneously (El Mansour \& Mupinga, 2007). In such cases, students decide when to access material, resulting in more flexibility, which is especially critical for adult learners who have other significant time commitments. Fortune, Shifflett, and Sibley (2006) found that online students value this flexibility and convenience more than interaction with the instructor and/or classmates; this preference or need for flexibility may even outweigh students' consideration of their own learning style (El Mansour \& Mupinga). In an online environment, learners can manage the pace of instruction so that it better suits their own style. Because students have more control over how, where and when to participate, web-based classes can lead to greater motivation to excel (St. Clair, 1999), and learning can be more active (Hacker \& Niederhauser, 2000) and more student-centered (Sanders, 2001) than traditional courses. However, other studies have identified numerous disadvantages of online education, including high drop-out rates and lack of student accountability (Sullivan, 2001). Performance results are mixed as to whether students do better academically in an online environment as compared to a more traditional setting. According to Carstens and Worsfold (2000), online courses fail to improve student learning, due at least in part to lack of face-to-face interaction with instructors and classmates. However, Sitzmann, Kraiger, Stewart, and Wisher (2006) found a small advantage for web-based instruction in learning declarative knowledge, and no difference for procedural knowledge or student satisfaction when compared to traditional instruction. Thus, online instruction may be better methodology for covering content typically taught via a lecture-based format (Jensen, 2011).

As mentioned, hybrid classes combine features of traditional F2F classes and online courses, and when designed carefully can promote active student learning (Riffell \& Sibley, 2005). Typically, students can access information, concepts and procedures outside of the classroom prior to the class session, which can allow for more in-depth processing activities during class time (El Mansour \& Mupinga, 2007). This allows for interaction between students and instructor while reducing - but not eliminating — time spent in the classroom (Twigg, 2003). In a study by Lin (2008), students in a hybrid class reported having increased individual contact with the instructor, albeit not all faceto-face (Jensen, 2011). Some students prefer not to draw attention to themselves by asking questions in front of the their peers, and are more comfortable seeking individual help outside of the classroom or through the use of email. Of significance, faculty have reported that the hybrid model allows them to accomplish learning objectives more successfully than in an entirely online or traditional class (Amrein-Beardsley, Foulger, \& Toth, 2007). Further, faculty who have supplemented traditional in-person methods with web-based activities and resources have made their classes more accessible and interactive, which can increase student interest and self-exploration. (AmreinBeardsley et al., 2007). Irons, Keel, and Bielema (2002) suggested that hybrid courses have the potential to accommodate various learning needs of students by using multiple delivery modalities. But hybrid courses can also create new challenges for students. Learners must possess some technological ability (El Mansour \& Mupinga, 2007). In addition, students presented with outside material may underestimate the value of attending class, thereby missing some active learning exercises aimed at developing necessary skills. Students may also misinterpret the online component of a class as being meaningless or menial (Lin, 2008). Further, students may choose to access only material that requires less time (Grabe \& Christopherson, 2008). Nevertheless, students should not be viewed 
as a homogenous group, but instead as individuals with different learning habits and styles, preferences and needs (Beyth-Marom, Saporta, \& Caspi, 2005). Likewise, students should be given as many choices as possible with respect to the availability and organization of learning opportunities (Bonk, Olson, Wisher, \& Orvis, 2002). This call for alternative learning opportunities to meet the needs of students having different expectations provides the motivation for the present study.

\section{PRIOR RESEARCH}

There is considerable pedagogical research investigating the advantages and disadvantages of traditional versus more technology-integrated education, some of which is described below. Dey et al. (2009) invited students who were enrolled in the first of a two-course physics sequence to participate in their study on the use of technology. The students chose one of the three groups offered for the 9 days of the study: those who attended the live presentation of the class (control group), those who watched a recording of the live presentation (personalized video), and those who watched a recording of only the presentation slides along with the instructor's voice (neutral video). Their study focused on the quality of learning related to students being able to see the lecturer or not. Students perceived the live presentation as being significantly higher in quality than the video groups, and the study showed "the quality variable was the most significant predictor of retention scores" (Dey et al., 2009, p. 391).

Gupta and Saks (2013) designed a study to examine why students choose to attend live lectures, how they use recorded lectures, and if the use of the recorded lectures affects their attendance at the live lecture. The study included 140 first-year and 119 second-year medical students enrolled in sequential patient-centered medicine courses who completed 15-minute surveys at the end of the academic year. The study found the reasons for students to attend or not attend a live lecture related to learning the material. If the material was difficult to learn or was visual in nature, students often chose to attend the live lecture. If the material was easily learned through textbooks or handouts, students were less likely to attend the live session.

Yoon and Sneddon (2011) wanted to know how the availability of tablet PC recorded lectures affected attendance of live lectures, how and why students utilized recorded lectures, and how watching recorded lectures affected student achievement. The students in this study were enrolled in one of two undergraduate mathematics courses, with Course B being more advanced than Course A. Students completed a survey after the completion of the class. Of the students who had watched at least one recorded lecture, $70 \%$ in Course A and $81 \%$ in Course B stated they watched the recording to enhance the live lecture. The remaining students who had watched the recordings stated it was to replace attending the live lecture. Responses to the survey suggested that students wanting enhancement from the recorded lectures were primarily looking for clarification of something not understood during the live lecture $(74 \%$ and $84 \%$, respectively). Students also acknowledged they watched the recordings as an aid in preparation for exams ( $51 \%$ and $40 \%$, respectively).

The results from the Yoon and Sneddon (2011) study regarding grades were based only on the first group (Course A) due to the smaller size of group B not having enough statistically significant factors. The researchers converted the grades (A+to D-) into a nine-point scale with an $\mathrm{A}+$ having a value of nine. Intentionally skipping live lectures because recorded lectures were available was not significantly associated with grades. Students who intended to watch more recordings than they actually did earned on average 1.66 grade points less than those who did not. Watching lectures just to watch them again or watching the lectures more than one time did not affect grades. Watching recorded lectures to go over material not understood during the live lecture was associated with higher grades. The level of lecture attendance did correlate with grades; however, the authors concluded this could also be a reflection of the students' commitment to the course and their desired grades in general, and not on the quality of the lectures.

Jensen's 2011 study involved 115 students enrolled in an introductory psychology class. The study took place over 4 weeks and four chapters with half of the class assigned to attend a live lecture and half of the class assigned to watch the recorded lecture, with them swapping roles each week. Each half of the class participated in both live lectures and recorded lectures twice over the 4-week study (two chapters under each of the methods). The recorded lectures were as close to the live lectures as possible. Students scheduled to watch the recorded lecture were encouraged to attend an active learning session during the time they did not have to attend the live presentation. 
These active learning sessions focused on application of material and included watching additional videos, demonstrations, group discussion, and other activities related to the material. Jensen's results showed no advantage in attending the live lectures over watching the recorded lectures or vice versa, although most students indicated the live lectures were more helpful in their learning the course material. Students indicated on the open-ended question segment of the questionnaire that they liked the recorded lectures for convenience, and liked the interaction and greater engagement from the live lectures. The study also found attendance at live lectures and watching recorded lectures both decreased during the study, suggesting hybrid courses may lead to an overall decrease in effort by some students.

\section{PRESENT STUDY}

In spring 2015 an experienced professor teaching two F2F sections of a senior-level federal individual income tax course at a mid-sized Midwest university provided students access to over 11 hours of instructor-recorded lectures as part of the course materials. The recordings covered some introductory material and content found in the 12 assigned chapters. Thirty-three lectures averaging 20 minutes in length and ranging from 15 to 20 minutes in duration were accessible. As a general rule, two or three separate recordings were available for each chapter, although for two chapters only one lecture was provided, and for another two chapters, four lectures were available. Each lecture covered the rules applicable to multiple topics and followed PowerPoint slides the instructor had made available. The recordings did not include coverage of the assigned homework problems. The main campus section had an enrollment of 43 , while the satellite campus section had 25 students. The main campus section met three times per week for half of the semester, and the satellite section met for a longer period once per week for the entire semester. The professor did not utilize the recordings or the PowerPoint slides during class. Students were informed they could use the additional materials in any manner they chose, including not at all. During class times the instructor covered assigned homework problems and answered questions. Students were expected to come to class prepared to discuss the day's assignment and to answer questions voluntarily. Students received no points for completing the assigned homework or for viewing the lectures or for class participation, although the syllabus did indicate that participation would be an important determination of borderline final grades.

At the end of the semester, students were invited to complete a survey worth several bonus points (approximately $2 \%$ of the total points available for the course). Alternatively, the students could write a brief memo on a deferred tax topic in exchange for the points. Of the 43 on-campus students, $38(88 \%)$ completed the questionnaire, while all 25 off-campus students $(100 \%)$ returned the survey, resulting in 63 usable responses. None of the other five students chose to complete the alternative project. There was no identifying information on the surveys, and the results from the two surveys were aggregated prior to analysis. With respect to demographic characteristics of the respondents, $39(62 \%)$ of the students who completed the survey were female, while $24(38 \%)$ were male. Further, $37(59 \%)$ of the students considered themselves to be traditional students, while $26(41 \%)$ identified themselves as being nontraditional. As to grade point average (GPA), 25 students (40\%) reported having a GPA between 3.7 and 4.0, $17(27 \%)$ reported a GPA of 3.4 to $3.69,12(19 \%)$ indicated they had a GPA of 3.1 to 3.39 , and nine (14\%) reported having a GPA of 2.8 to 3.09 . At the time they completed the survey, $23(36 \%)$ students anticipated receiving an A for the course, while $26(41 \%)$ expected to receive a B and $13(21 \%)$ thought they would receive a C. Only one student (2\%) anticipated receiving a lower than average grade. In addition, 43 students $(68 \%)$ indicated the course was much more difficult than the other courses they were taking, while $20(32 \%)$ indicated that it was somewhat more difficult; no one responded that the class was either somewhat or much less difficult. In terms of work, 32 students $(51 \%)$ responded that the class required much more work than their other courses, $23(36 \%)$ replied that it involved somewhat more work, and $8(13 \%)$ indicated that it was about the same amount of work.

The responses to substantive questions found in the survey will now be discussed.

\section{RESULTS}

As part of the questionnaire, students were asked about their usage of the recorded lectures and their perceptions of the value of the recordings. In addition, students were asked how the availability of the supplemental lectures impacted their behavior and satisfaction with the course and the professor. The usage section summarizes the frequency, timing and purpose with which students viewed the recorded lectures. The value section reflects student 
opinions as to the quality of the recordings and the impact on their study efforts and exam performance. The behavior section examines how the availability of recorded lectures impacted student attendance and their level of preparation. Finally, student satisfaction with the course and the instructor is reported.

\section{Usage}

Students were asked how many of the 33 recorded lectures they viewed during the semester. Possible responses included none, approximately $25 \%$, approximately $50 \%$, approximately $75 \%$, and all. As shown in Table 1 , Panel A, a significant majority of the 63 respondents watched at least some of the recordings. Panel B reports usage based on student gender, with female students reporting slightly more usage than males. Usage by nontraditional and traditional students (Panel C) was comparable. Finally, Table 1, Panel D provides the extent of usage by students expecting to receive a particular grade.

Table 1. Student Usage of Available Recorded Lectures

\begin{tabular}{|c|c|c|c|c|c|}
\hline & None & Approximately $25 \%$ & Approximately 50\% & Approximately $75 \%$ & All \\
\hline & 14 & 12 & 5 & 16 & 16 \\
\hline \multicolumn{6}{|c|}{ Panel B: Gender Distribution of Student Viewing Reports } \\
\hline & None & Approximately 25\% & Approximately 50\% & Approximately $75 \%$ & All \\
\hline Female & 9 & 6 & 3 & 12 & 9 \\
\hline Male & 5 & 6 & 2 & 4 & 7 \\
\hline \multicolumn{6}{|c|}{ Panel C: Student Age Distribution of Student Viewing Reports } \\
\hline & None & Approximately 25\% & Approximately 50\% & Approximately $75 \%$ & All \\
\hline Nontraditional & 5 & 4 & 3 & 6 & 8 \\
\hline Traditional & 9 & 8 & 2 & 10 & 8 \\
\hline \multicolumn{6}{|c|}{ Panel D: Expected Course Grade Distribution Viewing Report } \\
\hline & None & Approximately $25 \%$ & Approximately 50\% & Approximately $75 \%$ & All \\
\hline A & 6 & 3 & 2 & 4 & 8 \\
\hline B & 5 & 4 & 2 & 10 & 5 \\
\hline $\mathrm{C}$ & 3 & 4 & 1 & 2 & 3 \\
\hline
\end{tabular}

Further examination of the responses of the 14 students who indicated they did not watch any lectures revealed that $5(36 \%)$ had a grade point average (GPA) of 3.7 or above, $5(36 \%)$ had a GPA between 3.40 and $3.69,1(7 \%)$ had a GPA between 3.10 and 3.39, and $3(21 \%)$ had a GPA between 2.80 and 3.09. Alternatively, of the 25 students who reported having a GPA of 3.70 or above, $6(24 \%)$ reported they had watched all of the lectures, $9(36 \%)$ watched approximately $75 \%$ of the lectures, $3(12 \%)$ watched roughly half of the lectures, $2(8 \%)$ watched $25 \%$, and $5(20 \%)$ watched none.

As to those who viewed the recordings, several observations can be made as to their demographic characteristics. With respect to gender, $62 \%$ of females reported that they watched at least half of the lectures, compared to $54 \%$ of males. Considering the nontraditional versus traditional self-characterization, $64 \%$ of the traditional students, perhaps those more familiar with technology, viewed at least half of the lectures, as compared to $54 \%$ of the nontraditional students. More striking, $69 \%$ of students having grade point averages of 3.4 and above watched at least half of the lectures, compared to $38 \%$ of those with a GPA of less than 3.4 . Finally, $61 \%$ of the students expecting to receive an $\mathrm{A}$ for the course watched half or more of the lectures, compared to $64 \%$ of those anticipating a B and $43 \%$ expecting to receive a grade of $\mathrm{C}$ or lower.

Students who did not watch the lectures were asked to identify the primary reason out of several provided as to why they chose not view them. All but one (13, or $93 \%$ ) responded that they chose to study other material, while the remaining student (7\%) marked "other" as her answer, explaining that she "did not miss any of the live lectures." No one marked either of the other possible responses; that is, they ran out of time or they thought that the recordings would not be helpful. 
The 49 students who watched at least one of the lectures were asked to indicate when they generally viewed them. Eleven of these students provided more than one answer. Responses are found in Table 2. The majority of reported viewings took place prior to a chapter being covered and before the final exam. Of these 49 students, $42(86 \%)$ indicated that they watched the lectures as a general review of the material, while $7(14 \%)$ indicated that they watched parts of the recordings in order to review specific topics.

Table 2. Timing of Student Viewings (Multiple responses allowed)

\begin{tabular}{|c|c|}
\hline & Number of Responses \\
\hline Viewed the recordings right before the chapter was covered & 22 \\
\hline Viewed the recordings right before the final exam & 22 \\
\hline Viewed the recording right after the chapter was covered in class & 14 \\
\hline Viewed the recordings after missing a class & 14 \\
\hline
\end{tabular}

Value

Students who watched the recordings also were asked to rate the quality of the lectures and to indicate whether the lectures had value; that is, did the recordings impact their learning, study practices and performance. Most students (37) rated the recordings as good, while 11 students rated them as okay. Only one student thought the taped lectures were not very good. Table 3 summarizes student perceptions of the value of the recordings.

Table 3. Student Perception of Value of Recorded Lectures

\begin{tabular}{ccc}
\hline Panel A: Student Opinions of Value in Understanding Material & \\
\hline A Lot of Help & Some Help & Unsure \\
\hline 24 & 23 & 2 \\
\hline
\end{tabular}

Panel B: Student Opinions of Impact of Recorded Lectures on Their Studying Efficiency

\begin{tabular}{c|c|c|c}
\multicolumn{2}{c}{ Panel B: Student Opinions of Impact of Recorded Lectures on Their Studying Efficiency } \\
\hline Much More Efficient & Somewhat More Efficient & Somewhat Less Efficient & No Effect \\
\hline 16 & 28 & 1 & 4 \\
\hline
\end{tabular}

\begin{tabular}{cc|c|c|c|}
\hline \multicolumn{2}{|c|}{ Panel C: Student Opinions of Impact on Amount of Time Spent Studying for the Final Exam } \\
\hline $\begin{array}{c}\text { Spent Much More } \\
\text { Time }\end{array}$ & $\begin{array}{c}\text { Spent Somewhat } \\
\text { More Time }\end{array}$ & $\begin{array}{c}\text { Spent Somewhat Less } \\
\text { Time }\end{array}$ & $\begin{array}{c}\text { Spent Much Less } \\
\text { Time }\end{array}$ & $\begin{array}{c}\text { Had No Effect on } \\
\text { Amount of Time Spent }\end{array}$ \\
\hline 5 & 15 & 15 & 1 & 26 \\
\hline
\end{tabular}

Panel D: Student Perceptions of Impact of Recorded Lectures on Final Exam Performance

\begin{tabular}{ccc} 
Would Help A Lot & Would Help Some & Would Not Help \\
\hline 20 & 27 & 2 \\
\hline
\end{tabular}

Overall, the recorded lectures were perceived as having value. Specifically, the recordings aided student understanding of the material (Panel A), made studying more efficient (Panel B), and improved perceived performance on the final exam (Panel D). The responses generally suggest that the recordings didn't significantly impact the amount of time students spent studying (Panel C). As a side note, watching the recordings was identified by the respondents as being the fifth most relied on method to study for the final exam, following (1) re-doing assigned homework problems and reviewing (2) instructor-created PowerPoint slides, (3) the instructor's homework answers and (4) their own notes; lesser-used study techniques including re-doing practice quizzes and re-reading assigned chapters

\section{Behavior}

Making recorded lectures available has the potential to negatively impact student preparation and attendance. Of the 63 students who completed the questionnaire (which was administered after the last class but before the final exam), $7(11 \%)$ indicated that they always came to class prepared and $48(76 \%)$ responded that they usually came to class prepared. In contrast, 7 students $(11 \%)$ indicated they seldom came to class prepared, while $1(2 \%)$ reported she was never prepared for class. Table Four provides a breakdown of the viewing habits of the students based on their selfdescribed level of preparation. Of the eight students who reported little or no preparation, all indicated some use of 
the recordings. By comparison, all 14 of the students who indicated they had not viewed any of recorded lectures reported that they always (1) or usually (13) came to class prepared. It appears in general that the recordings did not keep most students from coming to class at least somewhat prepared. No assumptions can be made as to whether those who didn't come to class prepared would have done so had the recordings not been available.

Table 4. Student Usage of Available Recorded Lectures by Level of Preparedness

\begin{tabular}{l|c|c|c|c|c}
\hline & None & Approximately 25\% & Approximately 50\% & Approximately 75\% & All \\
\hline Always & 1 & 3 & 0 & 1 & 2 \\
\hline Usually & 13 & 8 & 4 & 12 & 11 \\
\hline Seldom & 0 & 1 & 1 & 2 & 3 \\
\hline Never & 0 & 0 & 0 & 1 & 0 \\
\hline
\end{tabular}

Further, 59 of the respondents (94\%) indicated that the availability of the recordings did not cause them to miss more class than they would have otherwise, while $4(6 \%)$ did respond that having access to the lectures caused them to miss more classes. Over half (32) of the students reported that they did not miss any classes, while 23 indicated they missed one or two classes, 7 indicated they missed three or four classes, and 1 reported missing more than four classes.

\section{Satisfaction}

Faculty members may have concerns that the practice of providing recorded lectures will have a negative impact on student evaluations of the course and instructor, especially when they themselves question the quality of the recordings. In this study, students reported that the recordings caused them to rate both the course and instructor the same or higher as they would have otherwise. Twenty-six students $(41 \%)$ indicated that they rated the course higher than they otherwise would have because of the availability of the recordings, while 37 (59\%) responded that the recordings had no impact on their course rating. No one indicated that they gave the course a lower rating due to the presence of the recorded lectures. With respect to their evaluation of the instructor, 24 students $(38 \%)$ indicated that the recordings caused them to rate the instructor higher, while 39 students $(62 \%)$ said the lectures had no impact on their rating of the instructor. Again, no students indicated the recordings caused them to rate the instructor lower. Also construed as a positive, $57(90 \%)$ of the students thought the instructor should continue to use recorded lectures in future classes. While six $(10 \%)$ of the students indicated their usage should be discontinued, none had viewed the recordings.

\section{CONCLUSION}

The use of technology in delivering courses continues to grow, despite resistance by some faculty to embrace it. Hybrid courses combine elements of a traditional F2F class with those of online courses, and if designed properly, can offer advantages over the latter two types and appeal to students with different learning styles. Students can access material prior to attending class, freeing up valuable time to engage in active learning activities that take place during the meeting time. However, there is concern that students may not recognize the significance of the online component of the class, and may also be less motivated to attend class.

In this study, the instructor of an undergraduate tax class made over 30 recorded lectures available but did not require students to view them. The professor hoped that the usage of the recordings would focus students' attention on the content he thought was the most important and would allow for prior review of that material before it was covered. At the same time, the instructor also hoped the availability of the recorded lectures would not detract from the students' pre-class preparation or their engagement in classroom discussions or provide an excuse not to attend class or pay attention. The recordings were intended to be supplemental and not designed to serve as a substitute for formal classroom lectures. Class time was instead primarily used to answer assigned homework problems.

In general, the responses to the survey as reported previously suggest that most students viewed at least some of the recordings most commonly before a chapter was covered and before the examination was administered and as a general review of the material. In general, a higher percentage of "traditional" students, students with higher grade point averages and those with higher grade expectations used the recordings. Most students reported that the 
recordings helped them understand the material and made studying more efficient. In addition, while viewing the recordings did not have a significant impact on the amount of time most students studied, most of the respondents believed the recordings would have a positive impact on their exam performance. Further, most students indicated that the availability of the supplemental material did not cause them to miss more class. Finally, the availability of the recordings generally had a positive impact on student ratings of the course and instructor.

There are limitations associated with this study. It involved only two class sections, both taught by the same professor who also recorded the lectures. In addition, the classes were not offered following a consistent structure; that is, the off-campus class met once a week for the entire semester while the on-campus class met three times a week during the last half of the semester. Further, the demographic characteristics of the students taking the classes were different. For example, 17 of the 25 students in the off-campus section considered themselves to nontraditional, while nine of 38 of on-campus students identified themselves as such. In addition, the instructor provided no options as to how to use the recordings, and posted all of them outside of the classroom at the beginning of the semester. Furthermore, the instructor did not require students to view them, and did not directly question or test students over material that was specifically covered in the recordings.

The results of this study provide opportunities for future research. At present, we are exploring how demographic differences among the respondents may have affected their usage and perceptions of the value of recordings. Changing the parameters of the study could also affect the usage and perceived value of the recorded lectures. For instance, administering quizzes over some of the recordings but not others might affect both their usage and perceived value.

\section{AUTHOR BIOGRAPHIES}

Thomas L. Davies, Black Hills Corporation Distinguished Professor of Accounting, serves as chair of the Division of Accounting and Finance at the University of South Dakota. He teaches undergraduate financial accounting and undergraduate and graduate tax classes. He received his LL.M. in Taxation from the University of Missouri-Kansas City in 1992. E-mail: tdavies@usd.edu (contact author)

Vonda K. Cotton is enrolled in the Master of Professional Accountancy program at the University of South Dakota and is a research assistant. A non-traditional student, she has accounting experience in manufacturing and agricultural industries. She will graduate with her MPA in December of 2016. After completing the CPA exam, she plans to pursue her doctorate in accounting in 2017. While at USD, Ms. Cotton has earned numerous accolades, including recognition for academic achievement and leadership from the Division of Accounting and Finance and receiving the South Dakota CPA Society Accounting Program Completion Scholarship. E-mail: Vonda.Cotton@coyotes.usd.edu

Leon Korte is an Associate Professor of Accounting at the University of South Dakota. He teaches courses in graduate financial accounting and governmental accounting and undergraduate decision modeling. He received his Ph. D. in Accountancy from the University of Nebraska - Lincoln in 1992. E-mail: 1korte@usd.edu

\section{REFERENCES}

American Council on Education (2005). To touch the future: Transforming the way teachers are taught. Washington, DC: Author. Retrieved from http://www.acenet.edu/resources/presnet/teacher-ed-rpt.pdf

Amrein-Beardsley, A., Foulger, T .S., \& Toth, M. (2007). Examining the development of a hybrid degree program: Using student and instructor data to inform decision-making. Journal of Research on Technology in Education, 39, 331-357.

Beyth-Marom, R., Saporta, K., \& Caspi, A. (2005). Synchronous vs. asynchronous tutorials: Factors affecting students' preferences and choices. Journal of Research on Technology in Education, 37, 245-262.

Bonk, C., Olson, T., Wisher, R., \& Orvis, K. (2002). Learning from focus groups: An examination of blended learning. Journal of Distance Education, 17, 97-118.

Carstens, R. W., \& Worsfold, V. L. (2000). Epilogue: A cautionary note about online classrooms. New Directions for Teaching and Learning, 84, 83-87.

Clark, R. C., \& Mayer, R. E. (2007). E-learning and the science of instruction (2nd ed.). San Francisco, CA: Jossey-Bass. 
Dey, E., Burn, H., \& Gerdes, D. (2009). Bringing the classroom to the Web: Effects of using new technologies to capture and deliver lectures. Research in Higher Education, 50, 377-393. doi: 10.1007/s11162-009-9124-0.

Doering, A., Hughes, J., \& Huffman, D. (2003). Preservice teachers: Are we thinking with technology? Journal of Computing in Teacher Education, 35(3), 342-361.

El Mansour, B., \& Mupinga, D. M. (2007). Students' positive and negative experiences in hybrid and online classes. College Student Journal, 41(1), 242-248.

Fortune, M. F., Shifflett, B., \& Sibley, R. E. (2006). A comparison of online (high-tech) and traditional (high touch) learning in business communication courses in Silicon Valley. Journal of Education for Business, 81, 210-214.

Grabe, M., \& Christopherson, K. (2008). Optional student use of online lecture resources: Resource preferences, performance and lecture attendance. Journal of Computer Assisted Learning, 24(1), 1-10.

Gupta, A., \& Saks, N. S. (2013). Exploring medical student decisions regarding attending live lectures and using recorded lectures. Medical Teacher, 35(9), 767-771. doi: 10.3109/0142159X.2013.801940

Hacker, D. J., \& Niederhauser, D. S. (2000). Promoting deep and durable learning in the online classroom. New Directions for Teaching and Learning, 84, 53-64.

Ho, C. P., \& Burniske, R. W. (2005). The evolution of a hybrid classroom: Introducing online learning to educators in American Samoa. TechTrends: Linking Research \& Practice to Improve Learning, 49, $24-29$.

Irons, L. R., Keel, R., \& Bielema, C. L. (2002). Blended learning and learner satisfaction: Keys to user acceptance? USDLA Journal, 16(12). Retrieved from http://usdla.org/html/journal/DEC02_Issue/article04.html.

Jensen, S. A. (2011). In-class versus online video lectures: Similar learning outcomes, but a preference for in-class. Teaching of Psychology, 38(4), 298-302. doi: 10.1177-0098628311421336

Lin, Q. (2008). Student satisfactions in four mixed courses in elementary teacher education program. Internet and Higher Education, 11, 53-59.

Lorenzetti, J. P. (2004). For quality and cost effectiveness, build a hybrid program. Distance Education Report, 8(21), 1-2, 7.

McKeachie, W. J., Pintrich, P. R., Lin, Y., Smith, D. A. F., \& Sharma, R. (1986). Teaching and learning in the college classroom: A review of the research literature. Ann Arbor, MI: Regents of the University of Michigan.

Palmer, L., O’Donnell, J. M., Ren, D., \& Henker, R. (2014). Comparison of Nurse Anesthesia Student 12 Lead EKG Knowledge, Interpretation Skill, Satisfaction and Attitude: Traditional Instruction vs. Asynchronous Online Vide Lecture. MERLOT Journal of Online Learning and Teaching, 10(3), 420-435.

Riffell, S., \& Sibley, D. (2005). Using web-based instruction to improve large undergraduate biology courses: An evaluation of a hybrid course format. Computers \& Education, 44, 217-235.

Sanders, W. B. (2001). Creating learning-centered courses for the World-Wide Web. Boston, MA: Allyn \& Bacon.

Sitzmann, T., Kraiger, K., Stewart, D., \& Wisher, R. (2006). The comparative effectiveness of web-based and classroom instruction: A meta-analysis. Personnel Psychology, 59, 623-664.

St. Clair, K. L. (1999). A case against compulsory class attendance policies in higher education. Innovative Higher Education, 23, 171-180.

Sullivan, P. (2001). Gender differences and the online classroom: Male and female college students evaluate their experiences. Community College Journal of Research and Practice, 25, 805-818.

Tapscott, D. (1997). Growing up digital: The rise of the Net generation. New York, NY: McGraw-Hill.

Twigg, C. A. (2003). Improving learning and reducing costs: New models for online learning. Educause Review, $38,28-38$.

Yoon, C., \& Sneddon, J. (2011). Student perceptions of effective use of tablet PC recorded lectures in undergraduate mathematics courses. International Journal of Mathematical Education in Science \& Technology, 42(4), 425-445. doi: 10.1080/0020739X.2010.543165

Young, J. R. (2002). "Hybrid" teaching seeks to end the divide between traditional and online instructions. Chronicle of Higher Education, 48(28), 33. 
NOTES 